\title{
Complementary Feeding: Critical Considerations to Optimize Growth, Nutrition, and Feeding Behavior
}

\author{
Bridget E. Young $\cdot$ Nancy F. Krebs
}

Published online: 16 October 2013

(C) Springer Science + Business Media New York 2013

\begin{abstract}
This review focuses on complementary feeding (CF) in westernized settings where primary health concerns are risk of obesity and micronutrient inadequacy. The current evidence is reviewed for: (1) when CF should be introduced, (2) what foods (nutrients and food types) should be prioritized and avoided, and (3) how the infant should be fed. Special attention is paid to the underlying physiological differences between breast- and formula-fed infants that often result in distinctly different nutritional and health risks. This difference is particularly acute in the case of micronutrient inadequacy, specifically iron and zinc, but is also relevant to optimal energy and macronutrient intakes. Emphasis is placed on the complex interplay among infants' early dietary exposures; relatively high energy and nutrient requirements; rapid physical, social and emotional development; and the feeding environment-all of which interact to impact health outcomes. This complexity needs to be considered at both individual and population levels and in both clinical and research settings.
\end{abstract}

Keywords Infant growth - Complementary feeding · Iron · Zinc · Protein · Breastfeeding ·

Human milk Infant formula

B. E. Young · N. F. Krebs $(\square)$

Section of Nutrition, Department of Pediatrics, University of Colorado Denver School of Medicine, 12700 E 19th Ave,

Box C-225, Aurora, CO 80045, USA

e-mail: Nancy.Krebs@UCDenver.edu

B. E. Young

e-mail: Bridget.Young@UCDenver.edu

\begin{abstract}
Abbreviations
AAP American Academy of Pediatrics

CF Complementary feeding/food

EAR Estimated average requirement

HM Human milk

IGF-1 Insulin-like growth factor-1

LC-PUFA Long chain-polyunsaturated fatty acids

RDA Recommended dietary allowance

WHO World Health Organization

WIC Special Supplemental Nutrition Program for

Women, Infants, and Children
\end{abstract}

\section{Introduction}

The 18-month period of complementary feeding (CF), from approximately 6 to 24 months of age, is the largest proportion of the "1,000 day Critical Window". During these dynamic months, the infant must transition to consuming a variety of textures and types of foods while meeting relatively high nutrient requirements, and to developing autonomy and exerting preferences and self-feeding skills. This period is also crucial for establishing and/or maintaining an appropriate trajectory of growth, both linear and ponderal.

Despite the importance of this period, the evidence base for best practices in CF is limited primarily to observational data. This review will focus on westernized nations where excess infant weight gain and subsequent obesity are primary outcomes of concern, as opposed to growth faltering in developing nations [1]. Historically, considerations of the impact of diet after early infancy have not typically distinguished or controlled for breastfeeding versus formula feeding, or a combination thereof. Yet this fundamental consideration is critical for both CF timing and food (or supplement) choices. For simplicity, this 


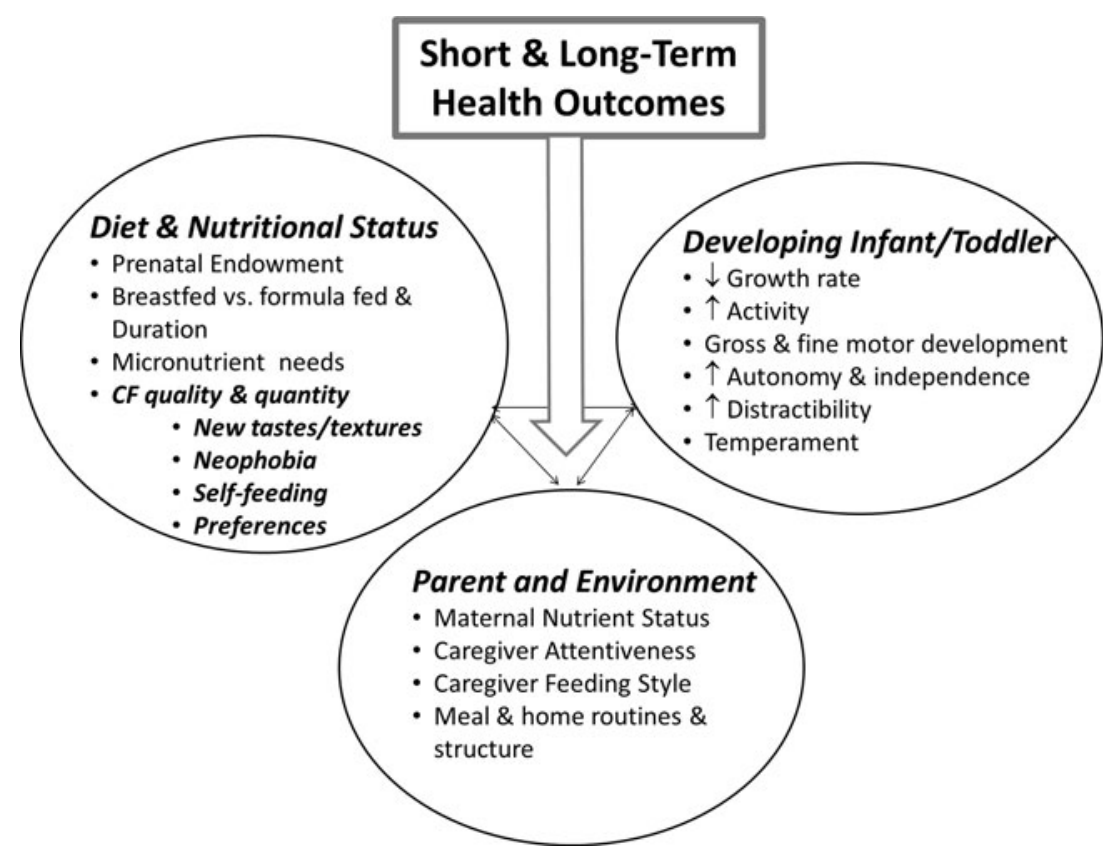

Fig. 1 Factors influencing health outcomes during the CF window. This figure demonstrates the inter-connected and complex inputs that affect the health outcomes associated with the CF period. A common clinical example of this interplay is the predominantly breastfed infant that exhibits growth faltering without any detectable underlying medical problem. In such cases, it is often due to a combination of

review will address breastfed and formula-fed infants as distinct groups, acknowledging that feeding occurs along a spectrum between these two feeding modes. Herein, the term "complementary foods" (CF) refers to nutrient- and energy-containing solid or semi-solid foods (or liquids) fed to infants in addition to human milk (HM) or formula.

In this review, the evidence base for the broad areas of timing of CF; impact of macro- and micro-nutrient sources; nutritional risks; and feeding behaviors are discussed. This overarching framework reflects the premise that each of these areas are inter-connected and equally important to a healthy progression through a period of tremendous physical and social-emotional development (Fig. 1). Although intervention trials have been prioritized for discussion, the paucity of such data in the literature has inevitably resulted in inclusion of a broader evidence review.

\section{When}

The American Academy of Pediatrics (AAP) and numerous other organizations recommend exclusive breastfeeding for approximately 6 months, with a minimum of 4 months [2]. Whether 4 or 6 months is the ideal age for introduction of CF has remained controversial $[3,4]$, partially because of the small number of intervention trials that have predominantly low calorie $\mathrm{CF}$, modest $\mathrm{HM}$ intake, micronutrient deficiencies that impact infant temperament and growth, and a stressed feeding relationship resulting from parental frustration. In formula-fed infants, a more common concern is excessive infant weight gain, which can often be driven by a different combination of factors residing in all three of the categories shown above

randomized timing of introduction to solid foods $[3,5,6$, 7••]. For infants in westernized, hygienic settings, adverse impact on growth has not been identified for groups according to either interval $[7 \cdot \bullet, 8]$. However, in reality, over $50 \%$ of infants in the United States are reportedly fed

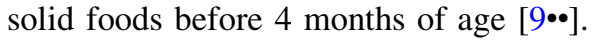

In developed countries, the major outcomes of concern that drive this controversy are infants' micronutrient status (namely, iron and zinc), risk of excessive weight gain and later obesity, and atopic disease. These risk factors differ by feeding mode (breast- vs. formula-fed). Two trials that randomized the timing of introduction of CF found early introduction (at 4 months) resulted in improved serum ferritin (i.e. iron storage) at 6 months among breastfed infants [7••], but did not impact the iron status of formula-fed infants, who are at minimal risk of micronutrient deficiencies [6].

The evidence for a relationship between timing of introduction of $\mathrm{CF}$ and infant obesity risk is equally conflicting. Some studies have failed to detect a relationship [10], while others report relationships with a variety of obesity outcomes at various time points [11-13]. Again, infant feeding mode may explain this variation. Two large cohort studies have reported that early introduction of $\mathrm{CF}$ was associated with increased odds of obesity at 3 years only among formula-fed infants [14•], and increased infant weight gain only among infants who were breastfed $<20$ weeks [15] 
As with all outcomes related to infant feeding, the initial feeding mode (breast vs. formula) and the individual infant's growth and risk must be considered beyond this 4-month period. Certain individuals or subgroups (e.g., breastfed infants at risk for micronutrient deficiency, late pre-term, or low birth weight infants) may benefit from introduction of specific CF before 6 months, although actual micronutrient deficiencies may be better addressed with therapeutic supplements.

\section{What-Energy and Nutrient Considerations}

\section{Energy}

Following the introduction of $\mathrm{CF}$, the caloric contribution of HM/formula often dramatically differs between breastfed and formula-fed infants/toddlers. The breastfed infant exhibits fairly tight self-regulation of energy intake, with decreasing consumption of $\mathrm{HM}$ in response to caloric intake from $\mathrm{CF}$ [16], even when breastfeeding frequency is maintained [3, 5]. A reduction in infant demand for $\mathrm{HM}$ will impact maternal milk supply so that caloric contribution from HM will tend to decrease as intake of solids increases. In one study, breastfed infants over 6 months of age decreased HM consumption more with calorically dense CF [17]. Despite compensatory decreases in HM consumption, high energy density CF resulted in higher total caloric intake and infant weight gain. This study objectively illustrates the complexity of the feeding environment and emphasizes that high (or low)-calorie foods can impact weight gain in the short term [17]. From a clinical standpoint, the imprecision of appetite and energy regulation is evidenced when predominantly breastfed infants exhibit growth faltering without any detectable underlying medical problem. In such cases, it is often due to a combination of predominantly low-calorie $\mathrm{CF}$, modest HM intake, micronutrient deficiencies (see below), and sometimes, a stressed feeding relationship.

This infant demand-maternal supply feedback system is lacking in formula-fed infants, and appetite regulation may be more easily over-ridden. For example, in formula-fed infants before 6 months, CF may be additive to rather than substitutive of the calories from formula [18], and may place certain infants at risk for excess weight gain [19]. The mechanisms whereby appetite and satiety may be deregulated, particularly in the formula-fed infant, remain unknown, but likely include a combination of the following: absence of biological feedback that reduces HM supply; exclusive bottle feeding [20, 21]; lack of exposure to bioactive components in HM that regulate appetite and satiety [22]; and varied satiety responses to different $\mathrm{CF}$ (high vs. low-calorie and liquids vs. semi-solids).
Irrespective of the mechanism, impaired appetite regulation may lead to excess caloric intake and weight gain. In one group of infants selected for familial risk of developing obesity, careful prospective determinations of energy intake and energy expenditure found that energy intake, not expenditure or parental adiposity, was predictive of body weight and adiposity at 1 and 2 years of age [23, 24]. The balance of energy density of CF and formula intake should be monitored after $\mathrm{CF}$ are introduced, to avoid overconsumption and excess weight gain.

\section{Fat}

In developed countries, concerns about pediatric overweight/obesity have drawn attention to the importance of the energy density of CF (as discussed above). HM and formula provide approximately $50 \%$ of calories from fat, although there is inherently more fluctuation in the fat content of HM. During the period of $\mathrm{CF}$, it is recommended that infants transition to a diet consisting of 30-40\% calories from fat [25] with a gradual reduction to 20-30\% calories from fat by year 2 [26]. While median intakes of fat among US toddlers are within these guidelines, approximately one-quarter of toddlers consume diets below the recommended range of fat, while only $3 \%$ exceeded the recommended range [27]. The traditional emphasis placed on cereal, fruits, and vegetables as first foods, all of which are low in fat, contributes to an overall sharp reduction in the percentage of energy from fats in older infants and may be associated with inadequate energy intake, especially in those who are breastfed.

Both the quantity and quality of fat in the transitional diet are relevant. The quality of dietary fat is critical to provide optimal intakes of essential and beneficial fatty acids. Breast milk and most infant formulas are rich sources of long chain-polyunsaturated fatty acids (LCPUFAs). However, intake of these lipid components dramatically decreases as $\mathrm{HM}$ and formula consumption wanes [28]. Higher intakes of LC-PUFA at 14 months of age have been associated with lower risk of overweight at the age of preschool [29], yet interventions manipulating the type of dietary fat in CF have been very limited. A fish oil supplementation trial from 9 to 12 months of age $(5 \mathrm{~mL}$ daily) resulted in increased serum cholesterol, decreased systolic blood pressure, decreased serum triglycerides over time [30], and improved immune response [31] in supplemented infants. Avoidance of saturated fat and cholesterol may also be an effective early strategy for reduction of cardiovascular disease risk. The famous "STRIP" (Special Turku Coronary Risk Factor Intervention Project) trial, initiated at 7 months of age, counseled intervention families to decrease infant saturated fat and cholesterol intake while improving intake of PUFAs, vegetable oils, and skim 
milk after 12 months [32]. These infants grew similarly to control infants, and exhibited lower serum cholesterol at 13, 24, and 36 months [33]. Notably, both intervention and control infants exhibited quite low fat intakes $(<30 \%$ energy from calories) at 8 and 13 months, and had marginally adequate intakes of vitamin D and iron [33-35]. Longer-term follow-up of this cohort has demonstrated favorable effects on obesity and cardiovascular health status [36, 37].

These studies collectively confirm nutrient-rich sources of fat that provide essential and beneficial fatty acids (e.g., LC-PUFA) and micronutrients provide health benefits and diminish future disease risk. No current evidence indicates adverse outcomes from fat intakes within the recommended range of 30-40 \% of energy from fat. Indeed, a relatively generous dietary fat intake from nutrient dense sources may also foster healthy growth and ensure micronutrient sufficiency without placing infants/toddlers at risk for excessive weight gain [24, 29]. However, a wellselected lower fat intake ( $<30 \%$ of calories from fat) can also be safe and adequate for normal growth and development when emphasis is placed on nutrient dense CF that provide adequate energy and meet requirements for micronutrients and essential fatty acids. In instances of excessive weight gain, a reduction in fat intake (especially saturated fats), is an appropriate intervention to reduce overall energy intake [26].

\section{Protein}

"High protein" intake has been cited as a risk factor for excessive weight gain during the $\mathrm{CF}$ period, but the basis for this concern has several important nuances. Building on early observational data that suggested a relationship between protein intake during the first 2 years of life with fatness at later childhood [24, 38-40], a large European trial randomized infants within the first 2 months of life to infant formulas with different concentrations of cow milk protein through the first year [41]. Infants who received the high protein formula had greater weight gain and weight relative to length by 6 months. The primary divergence occurred during the first 6 months, peaked at 12 months, and persisted over the 2-year follow-up period [41]. In a non-random subgroup, higher protein intake was associated with higher weight velocity in the first 6 months, which was correlated with fat mass at 6 months, which in turn correlated with BMI at 6, 12, and 24 months [42]. Notably, the amounts of protein in the high protein formulas were very high, leading to intakes well above typical intakes.

The type of protein source is likely critical: only dairy protein has been demonstrated to promote higher growth rates. The exact mechanism is unknown; stimulation of both the insulin-like growth factor-1 (IGF-1) axis and insulin activity have been documented [43]. In one shortterm randomized trial, cow milk (vs. infant formula) was assigned as a CF between 9 and 12 months of age [44]. No effect on growth was observed but the percentage of energy from cow milk protein was associated with IGF-1 levels. Although the results were attributed to the short duration and relatively small sample size, they may also reflect different susceptibility of breastfed infants to protein source compared to formula-fed infants, since the protein intake from HM is considerably lower than that of typical infant formulas.

Although few trials have been conducted to examine the effects of meat on growth, the existing data do not suggest a growth-stimulating effect of meat when used as a CF in healthy breastfed infants [45, 46, 47••], nor in stunted breastfed infants [48••]. The difference in effect of dairy versus meat protein is further supported by a study in 8-year-old children in which dairy was associated with higher IGF-1 concentrations compared to high protein intake from meat [49].

Based on concerns of obesigenic effects, a maximum intake of $15 \%$ of total energy from protein has been recommended for later infancy and the second year of life, with particular emphasis on limiting dairy protein $[50,51]$. Prospective observational trials, however, have found conflicting results regarding protein intake and weight status at 2 years of age [24, 29, 51]. Median intakes of protein as a percentage of energy for older infants (6-11 months) and toddlers (12-24 months) in the US were 9 and $15 \%$, respectively [27]. In a randomized trial comparing meats versus fortified infant cereal as predominant $\mathrm{CF}$ for older breastfed infants, the percentage of energy from protein was 17 and 9-10\%, respectively, with no differences in growth or weight status [47••]. The optimal contribution of total protein to the weaning diet is thus debatable. Consideration of at least three factors is warranted for any recommendation: timing of exposure; source of protein; and host feeding status.

\section{Micronutrients}

The distinctions for breastfed versus formula-fed infants' CF needs are perhaps most notable in relation to the risk of micronutrient inadequacy. Fortification of all standard infant formulas with all essential micronutrients results in a minimal risk of deficiencies for healthy, term, formula-fed infants. This risk changes after 12 months of age, when most healthy toddlers have transitioned to family foods and no longer consume formula. U.S. survey data indicated that toddlers' average intakes of most micronutrients, including antioxidants, B vitamins, and other micronutrients, were adequate [27]. In contrast, older breastfed infants are clearly at risk for certain micronutrient deficiencies. Assuming 
maternal diet is adequate and unrestricted, the gap between potential intake from HM and the dietary requirement is highest for iron and zinc.

The older breastfed infant's need for iron from $\mathrm{CF}$ is dictated not only by dietary intake but by gestational age, complications of pregnancy (maternal iron deficiency anemia, diabetes), timing of umbilical cord clamping, postnatal growth rate, and duration of exclusive breastfeeding. For the healthy term exclusively breastfed infant, by at least 6 months of age, the infant will either need to consume iron-rich CF or receive iron supplements to support increasing erythropoiesis and normal brain development. The risks of iron deficiency and iron deficiency anemia progressively increase beyond 6 months [2]. National data indicate a prevalence of approximately $9 \%$ in 1-3 year olds in the U.S. In 9-month-old breastfed infants, rates of iron deficiency may be much higher: two prospective but relatively small studies in Denver observed rates of $\sim 30 \%[46,47 \bullet \bullet]$.

The recommended practice of introducing infant cereals as a first $\mathrm{CF}$ addresses the recognized need for iron. While commercial infant cereals in the U.S. are iron fortified, consumption of infant cereals has actually decreased in recent years [9*0]. The RDA of $11 \mathrm{mg} /$ day for infants $7-12$ months of age is based on the relatively low iron absorption from cereal [52]. In contrast, flesh foods, especially red meats, are naturally rich in heme iron, which has a much more favorable bioavailability (20-35\% absorption rate). Dietary intake alone, however, does not predict iron status: a threefold higher intake of iron from cereal compared to meats resulted in similar rates of iron deficiency in 9-month-old breastfed infants [47••]. Iron deficiency is associated with altered social and emotional development, including more hesitation and wariness, which may contribute to more cautious behavior in the feeding domain. No data have specifically linked food neophobia to iron deficiency, but an altered maternalinfant interaction is certainly plausible. In such cases, resistance to new foods at a critical period may prompt more intrusive and pressured feeding style by parents, and emphasizes the bi-directionality of feeding interactions [53] (Fig. 1).

The exclusively breastfed infant is also strongly dependent on $\mathrm{CF}$ to provide adequate zinc intake after approximately 6 months of age. Zinc fortification of infant cereals is not routine in the U.S., and traditional CF practices that emphasize infant cereals, fruits, and vegetables are not likely to meet the zinc requirements of the older breastfed infant. Meats (and liver) are the best CF source of zinc, but these are often delayed until late in the progression of CF. Prevalence data for zinc deficiency are lacking, in large part due to the lack of sensitive biomarkers of zinc status. Available data and clinical experience suggest, however, that zinc deficiency is relatively common in older breastfed infants and young children $[48 \bullet \bullet, 54,55]$. The effects of mild zinc deficiency are highly relevant to the $\mathrm{CF}$ period. Well before the development of the classic dermatitis of severe zinc deficiency, growth faltering and loss of appetite manifest [54]. These non-specific presentations are most likely to be identified as related to marginal zinc status only with recognition of a dietary pattern suggestive of inadequacy: breastfeeding or mixed diet without fortified formula or foods, and modest meat intake. As noted for iron, the physiologic signals associated with zinc deficiency, especially the anorexia, set the stage for perturbed feeding interactions and parental feeding styles.

\section{What-Food Considerations}

Vegetables, Fruits, and Juice

Infants should eventually be exposed to a wide variety of fruits and vegetables to increase incorporation of these foods into the child/adult diet. However, among U.S. infants between 6 and 18 months, between 28 and $37 \%$ of infants consume zero vegetables and between 10 and $23 \%$ consume zero fruits on any given day $[9 \bullet \cdot]$. While 4 ounces of $100 \%$ juice is considered a serving of fruit, excessive or constant consumption is discouraged in order to avoid excess simple sugar intake, dental caries, and displacement of more nutrient-dense foods [56, 57]. Some research suggests that overconsumption ( $\geq 340 \mathrm{~g}$ or $12 \mathrm{oz} / \mathrm{day}$ ) of $100 \%$ juice leads to shorter stature and/or increased obesity risk. This link remains controversial with several conflicting reports $[56,58,59]$, and may only be relevant to children who are already overweight [60]. Because of these risks, the AAP recommends that $100 \%$ fruit juice not be introduced before 6 months of age and be limited to

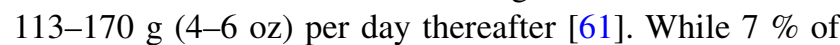
American infants receive juice before 6 months $[9 \bullet \cdot$, the prevalence of early introduction of juice, and overall consumption rates of juice have decreased since 2002 [9••]. Although fruit and vegetable consumption has been associated with lower total energy intakes for preschool age children, data related to intake from $\mathrm{CF}$ and weight status of infants and toddlers are not available [62].

\section{Sweet and Savory Snacks}

The combination of small gastric capacity and large nutrient $/ \mathrm{kg}$ demands leaves minimal margin for nutrientpoor dietary choices in CF. This is particularly relevant for breastfed infants who may be at increased risk for micronutrient deficiencies after 6 months, and for toddlers in the second year of life when consumption of fortified foods 
typically decreases. Sugar sweetened beverages including fruit drinks (vs. $100 \%$ fruit juice) displace more nutrient dense choices and may also contribute excess calories in the diet. Processed commercial toddler snacks and desserts, common in the older infant and toddler diet, are also often low in nutrient density and high in added sugars and sodium. The percentage of infants consuming sugarsweetened beverages or desserts on any given day at 6-9 and 9-12 months is 17 and $43 \%$ respectively, reaching $81 \%$ by 24 months [ $9 \cdot 0$ ]. Additions of sodium and sugar are not necessary to improve acceptance of new fruits and vegetables in older infants [63]. Despite this research, over $60 \%$ of baby and toddler foods contain either excess sodium and/or proportion of calories from sugar [64]. Since the development of long-standing preferences is built on familiarity, early and frequent exposures to highly palatable sweet and salty foods raises concern [65]. Furthermore, the potential for foods from this category to contribute to excessive energy intake during this critical period is quite high.

\section{How}

The third and equally important component of CF is how the infant and toddler are fed and allowed to develop feeding autonomy. Two overarching themes encompass this domain: (1) the physical environment and regular routines around eating; and (2) the behavioral aspects of parental feeding style and parent-infant interaction, including how the increasing autonomy of the toddler is managed in the feeding domain.

Commonplace and popular spill-proof, child-size handheld, lidded containers and squeezable packaging that allow liquids and pureed and semi-solid products to be eaten 'on the go' enable grazing behavior. Constant access to nutrient-poor foods (e.g., infant cookies, freeze-dried fruit and vegetable crisps, and caloric beverages) should be avoided, as this feeding pattern may foster poor eating habits, including eating in the absence of hunger, and may also interfere with consumption of foods offered at meal times.

A few studies have investigated how to introduce $\mathrm{CF}$ to improve infant acceptance. Both breastfed and formula-fed infants show improved acceptance of new foods with repeated neutral exposures, with or without an accompanying sweet fruit $[66,67]$. The importance of exposure is supported by trials demonstrating equal acceptance of pureed meats and infant cereals as a first CF in 6 month olds [46, 48]. Breastfed infants have been shown to exhibit larger intake of food after the same number of exposures compared to formula-fed infants [67]. This finding may be due to the fact that infants are exposed to flavor profiles of the maternal diet via amniotic fluid in utero and via breast milk post-natally. Such exposure may increase acceptance later during the period of $\mathrm{CF}[65,68,69]$.

A responsive feeding style is recommended, encouraging parents to respond to infant cues of both hunger and satiety [70, 71]. Inappropriate feeding behaviors, including both restrictive and indulgent/overly permissive parenting styles, have been associated with poor self-regulation of energy intake [65] and increased infant adiposity and overweight [72-74]. In a responsive feeding relationship, the caregiver ideally remains in an authoritative position, respecting the infant/toddler's developing autonomy, but not yielding full control to the child [75]. Interventions targeting feeding style have often resulted in subtle improvements in infant intake and parental behaviors and knowledge, but have generally not impacted infant growth or obesity risk [76, 77]. Rarely do these studies control for initial infant feeding mode, or consider micronutrient status. Maternal breastfeeding habits may also impact the degree of maternal control exerted during CF [78, 79]. Additional research suggests that infants who are breastfed for at least 6 weeks exhibit improved satiety responsiveness at 18-24 months [80]. As noted in the discussion of micronutrient deficiencies, disruptions of satiety signals can also adversely impact the feeding dynamic between infant and caregiver, which can progress to disordered feeding [53].

Several recent studies have incorporated a relatively holistic approach, educating parents extensively on both mechanical and behavioral components associated with ideal infant feeding patterns. Overall, the findings demonstrated a positive impact on parental responsiveness, but have reported mixed results on infant weight gain and child overweight [81-83].

\section{Conclusions}

Individualized nutrition begins in early infancy and involves the progressively complex interplay among infants' early dietary exposures; relatively high energy and nutrient requirements; rapid physical, social and emotional development; and the feeding environment, all of which interact to impact feeding and health outcomes (Fig. 1). Assessment of deviations in optimal growth and development must consider the potential impact of each of these domains. The differences between breastfeeding and formula feeding, and between breastfed and formula-fed infants are substantial (Table 1), and need to be considered on an individual basis. Furthermore, these differences should be acknowledged in population recommendations. As rates of exclusive breastfeeding and of extended duration of breastfeeding increase in westernized settings, the implications of these differences 
Table 1 Key points relevant to CF emphasizing the difference between breast and formula-fed infants

\begin{tabular}{|c|c|c|}
\hline & Breastfed infants & Formula-fed infants \\
\hline \multicolumn{3}{|l|}{ When $\mathrm{CF}$ are fed } \\
\hline Timing of $\mathrm{CF}$ & $\begin{array}{l}\text { Exclusive } \mathrm{BF} \geq 4 \text { months } \\
\text { In westernized settings, } \mathrm{CF} \text { at } 4 \text { months may enhance iron } \\
\text { status } \\
\text { No difference in growth with introduction of } \mathrm{CF} \text { at } 4 \text { vs. } \\
6 \text { months }\end{array}$ & $\begin{array}{l}\mathrm{CF}<4 \text { months associated with increased risk overweight } \\
\text { No effect on iron status of } \mathrm{CF} \text { at } 4 \text { months }\end{array}$ \\
\hline \multicolumn{3}{|l|}{ What $\mathrm{CF}$ are fed } \\
\hline Energy & $\begin{array}{l}\text { Increasing energy intake from CF substitutive: associated with } \\
\text { gradual reduction in HM intake } \\
\text { High caloric density CF are associated with increased caloric } \\
\text { intake; important implications for growth faltering }\end{array}$ & $\begin{array}{l}\text { Energy intake from CF may be additive to energy intake } \\
\text { from formula; less robust feedback between demand and } \\
\text { supply } \\
\text { Energy intake more predictive of overweight status at } 1 \text { and } \\
2 \text { years than expenditure }\end{array}$ \\
\hline Fat & $\begin{array}{l}\text { Fat intake from HM is variable across feeds, and across days } \\
\text { LC-PUFAs are present in HM } \\
\text { Carefully selected reduced fat intake associated with overall } \\
\text { long-term benefits including cardiovascular disease risk } \\
\text { Generous fat intake not associated with excessive weight gain }\end{array}$ & $\begin{array}{l}\text { Total fat intake relatively constant across all feeds; LC- } \\
\text { PUFA added to most infant formulas } \\
\text { Fat intake not predictive of overweight } \\
\text { Reduction in fat intake (especially saturated fat and } \\
\text { cholesterol) in context of excessive weight gain is safe }\end{array}$ \\
\hline Protein & $\begin{array}{l}\text { Quantity of protein in HM lower than standard infant formulas } \\
\text { Effects of cow milk protein on weight and adiposity gain are } \\
\text { blunted } \\
\text { High intake of protein from meat provides important source of } \\
\text { iron and zinc, with no association of growth or adiposity } \\
\text { stimulation }\end{array}$ & $\begin{array}{l}\text { Rapid gain in neonatal period associated with high protein } \\
\text { intake may hold greater risk for excessive growth and } \\
\text { adiposity compared to later exposure } \\
\text { Dairy protein more potent effect on growth stimulation than } \\
\text { meat }\end{array}$ \\
\hline Micronutrients & $\begin{array}{l}\text { Breastfed infants are at risk of developing micronutrient } \\
\text { inadequacy, especially iron and zinc; risk increases after } \\
\sim 6 \text { months without CF } \\
\text { Meat is an adequate source to help meet iron and zinc demands } \\
\text { Dietary intake of iron is not strongly predictive of iron status; } \\
\text { other determinants include prenatal risks, timing of cord } \\
\text { clamping, growth rate } \\
\text { Micronutrient deficiencies can impact all aspects of the feeding } \\
\text { domain }\end{array}$ & $\begin{array}{l}\text { Formula is generously fortified with all essential nutrients } \\
\text { Older infants/toddlers who no longer receive fortified } \\
\text { formula can develop micronutrient inadequacy, } \\
\text { particularly iron and zinc, depending especially on quality } \\
\text { of diet } \\
\text { Micronutrient deficiencies can impact all aspects of the } \\
\text { feeding domain }\end{array}$ \\
\hline $\begin{array}{l}\text { Fruits and } \\
\text { vegetables }\end{array}$ & $\begin{array}{l}\text { Many breast- and formula-fed infants are still failing to meet } \\
\text { vegetables } \\
\text { Excess juice consumption may displace more nutrient dense op } \\
\text { Excessive caloric beverage consumption may manifest as eithe }\end{array}$ & $\begin{array}{l}\text { ecommendations for intake and variety of whole fruits and } \\
\text { tions and should be limited according to recommendations } \\
\text { under- or overweight }\end{array}$ \\
\hline $\begin{array}{l}\text { Sweet and } \\
\text { savory snacks/ } \\
\text { desserts }\end{array}$ & $\begin{array}{l}\text { Excess consumption of nutrient poor snacks, especially } \\
\text { calorically dense snacks, may displace nutrient dense options } \\
\text { and increase the older breastfed infants' risk of micronutrient } \\
\text { inadequacy }\end{array}$ & $\begin{array}{l}\text { Frequent consumption of foods from this category can } \\
\text { easily contribute to excess caloric consumption and } \\
\text { weight gain and may impact long-term taste preferences }\end{array}$ \\
\hline \multicolumn{3}{|l|}{ How $\mathrm{CF}$ are fed } \\
\hline $\begin{array}{l}\text { Manner of } \\
\text { food } \\
\text { introduction }\end{array}$ & $\begin{array}{l}\text { Repeated and neutral exposures improve both acceptance and } \\
\text { food intake } \\
\text { Exposures to taste profiles in maternal diet via HM may also } \\
\text { improve acceptance }\end{array}$ & Repeated and neutral exposures improve acceptance \\
\hline Feeding style & \multicolumn{2}{|c|}{$\begin{array}{l}\text { A responsive feeding style should be encouraged in order to support infant developing autonomy and encourage the } \\
\text { development of healthy eating behaviors and patterns. Both overly restrictive and overly permissive feeding styles have } \\
\text { been associated with impaired and excessive growth }\end{array}$} \\
\hline Meal hygiene & \multicolumn{2}{|c|}{$\begin{array}{l}\text { Feeding behaviors such as constant grazing and unrestricted snacking may encourage development of poor meal hygiene and } \\
\text { undesirable behaviors such as eating in the absence of hunger, and/or contribute to dysfunctional child-parent feeding } \\
\text { relationship }\end{array}$} \\
\hline
\end{tabular}

$C F$ complementary feeding/foods, $L C$-PUFA long chain-polyunsaturated fatty acids, $H M$ human milk 
should be incorporated into clinical assessments and the anticipatory guidance provided to parents regarding the $\mathrm{CF}$ period. Micronutrient deficiencies at this age, particularly of iron and zinc, are not trivial or rare in these settings and often go unrecognized, especially among breastfed infants. Although the evidence base for CF continues to emerge, the importance of this developmental period warrants recommendations that accurately reflect the current state of knowledge.

Future research and interventions should also ideally address the complex intersection of environmental, behavioral, nutritional, and biological factors that impact outcomes specific to this period of development, as well as the longer-term health effects with their origins in early life (Fig. 1).

Acknowledgments This work was supported by NIH grant K24 DK083772 which supported NK and NIH grant T32 DK007658 which supported BY and NK.

Disclosure Nancy F. Krebs and Bridget E. Young declare that they have no conflict of interest.

Human and Animal Rights and Informed Consent This article does not contain any studies with human or animal subjects performed by any of the authors.

\section{References}

Papers of particular interest, published recently, have beenhighlighted as:

- Of importance

-• Of major importance

1. Dewey KG, Adu-Afarwuah S. Systematic review of the efficacy and effectiveness of complementary feeding interventions in developing countries. Matern Child Nutr. 2008;4(Suppl 1):24-85.

2. Baker RD, Greer FR. Diagnosis and prevention of iron deficiency and iron-deficiency anemia in infants and young children (0-3 years of age). Pediatrics. 2010;126(5):1040-50.

3. Cohen RJ, et al. Effects of age of introduction of complementary foods on infant breast milk intake, total energy intake, and growth: a randomised intervention study in Honduras. Lancet. 1994;344(8918):288-93.

4. Lanigan JA, et al. Systematic review concerning the age of introduction of complementary foods to the healthy full-term infant. Eur J Clin Nutr. 2001;55(5):309-20.

5. Dewey KG, et al. Age of introduction of complementary foods and growth of term, low-birth-weight, breast-fed infants: a randomized intervention study in Honduras. Am $\mathrm{J}$ Clin Nutr. 1999;69(4):679-86.

6. Kattelmann KK, Ho M, Specker BL. Effect of timing of introduction of complementary foods on iron and zinc status of formula fed infants at 12, 24, and 36 months of age. J Am Diet Assoc. 2001;101(4):443-7.

7. • Jonsdottir $\mathrm{OH}$, et al. Timing of the introduction of complementary foods in infancy: a randomized controlled trial.
Pediatrics. 2012;130(6): 038-45. This well-designed study provides objective data on impact of timing of complementary foods in a developed country setting.

8. Kramer MS, Kakuma R. Optimal duration of exclusive breastfeeding. Cochrane Database Syst Rev. 2009;8:CD003517.

9. $\bullet$ Siega-Riz AM, et al. Food consumption patterns of infants and toddlers: where are we now? J Am Diet Assoc. 2010;110(12 Suppl):S38-51. The size and rigor of this survey provides important insight into consumption patterns of infants and young children in the U.S.

10. Burdette HL, et al. Breastfeeding, introduction of complementary foods, and adiposity at $5 \mathrm{y}$ of age. Am $\mathrm{J}$ Clin Nutr. 2006;83(3):550-8.

11. Seach KA, et al. Delayed introduction of solid feeding reduces child overweight and obesity at 10 years. Int $\mathrm{J}$ Obes (Lond). 2010;34(10):1475-9.

12. Schack-Nielsen L, et al. Late introduction of complementary feeding, rather than duration of breastfeeding, may protect against adult overweight. Am J Clin Nutr. 2010;91(3):619-27.

13. Grote $\mathrm{V}$, et al. The introduction of solid food and growth in the first 2 $\mathrm{y}$ of life in formula-fed children: analysis of data from a European cohort study. Am J Clin Nutr. 2011;94(6 Suppl):1785S-93S.

14. - Huh SY, et al. Timing of solid food introduction and risk of obesity in preschool-aged children. Pediatrics. 2011;127(3):e544-51. While not an intervention, this was a large trial that analyzed breastfed and formula-fed infants separately. The analysis also controlled for infant weight gain, a powerful independent predictor of later obesity.

15. Baker JL, et al. Maternal prepregnant body mass index, duration of breastfeeding, and timing of complementary food introduction are associated with infant weight gain. Am J Clin Nutr. 2004;80(6):1579-88.

16. Wells JC, et al. Randomized controlled trial of 4 compared with 6 mo of exclusive breastfeeding in Iceland: differences in breast-milk intake by stable-isotope probe. Am J Clin Nutr. 2012;96(1):73-9.

17. Islam MM, et al. Effects of varied energy density of complementary foods on breast-milk intakes and total energy consumption by healthy, breastfed Bangladeshi children. Am J Clin Nutr. 2006;83(4):851-8.

18. Heinig MJ, et al. Intake and growth of breast-fed and formula-fed infants in relation to the timing of introduction of complementary foods: the DARLING study. Davis Area Research on Lactation, Infant Nutrition and Growth. Acta Paediatr (Oslo, Norway: 1992). 1993;82(12):999-1006.

19. Ong KK, et al. Dietary energy intake at the age of 4 months predicts postnatal weight gain and childhood body mass index. Pediatrics. 2006;117(3):e503-8.

20. Li R, et al. Do infants fed from bottles lack self-regulation of milk intake compared with directly breastfed infants? Pediatrics. 2010;125:e1386-93.

21. Disantis KI, et al. Do infants fed directly from the breast have improved appetite regulation and slower growth during early childhood compared with infants fed from a bottle? Int J Behav Nutr Phys Act. 2011;8:89-100.

22. Young, et al. Biological determinants linking infant weight gain and child obesity: current knowledge and future directions. Adv Nutr. 2012;3:675-86.

23. Stunkard AJ, et al. Energy intake, not energy output, is a determinant of body size in infants. Am J Clin Nutr. 1999;69(3):524-30.

24. Stunkard AJ, et al. Predictors of body size in the first $2 \mathrm{y}$ of life: a high-risk study of human obesity. Int J Obes Relat Metab Disord. 2004;28(4):503-13.

25. Institute of Medicine. Dietary reference intakes; the essential guide to nutrient requirements. Washington, DC: National Academy Press; 2006.

26. Daniels SR, Greer FR. Lipid screening and cardiovascular health in childhood. Pediatrics. 2008;122(1):198-208. 
27. Butte NF, et al. Nutrient intakes of US infants, toddlers, and preschoolers meet or exceed dietary reference intakes. J Am Diet Assoc. 2010;110(12 Suppl):S27-37.

28. Schwartz J, et al. PUFA and LC-PUFA intake during the first year of life: can dietary practice achieve a guideline diet? Eur J Clin Nutr. 2010;64(2):124-30.

29. Heppe DH, et al. Parental, fetal, and infant risk factors for preschool overweight: the Generation $\mathrm{R}$ Study. Pediatr Res. 2013;73(1):120-7.

30. Damsgaard CT, et al. Fish oil affects blood pressure and the plasma lipid profile in healthy Danish infants. J Nutr. 2006;136(1):94-9.

31. Damsgaard CT, et al. Fish oil supplementation modulates immune function in healthy infants. J Nutr. 2007;137(4):1031-6.

32. Simell O, et al. Special Turku Coronary Risk Factor Intervention Project for Babies (STRIP). Am J Clin Nutr. 2000;72(5 Suppl):1316S-31S.

33. Niinikoski $\mathrm{H}$, et al. Growth until 3 years of age in a prospective, randomized trial of a diet with reduced saturated fat and cholesterol. Pediatrics. 1997;99(5):687-94.

34. Niinikoski $\mathrm{H}$, et al. Intake and indicators of iron and zinc status in children consuming diets low in saturated fat and cholesterol: the STRIP baby study. Special Turku Coronary Risk Factor Intervention Project for Babies. Am J Clin Nutr. 1997;66(3):569-74.

35. Lagstrom $\mathrm{H}$, et al. Nutrient intakes by young children in a prospective randomized trial of a low-saturated fat, low-cholesterol diet. The STRIP Baby Project. Special Turku Coronary Risk Factor Intervention Project for Babies. Arch Pediatr Adolesc Med. 1997;151(2):181-8.

36. Hakanen M, et al. Development of overweight in an atherosclerosis prevention trial starting in early childhood. The STRIP study. Int J Obes (Lond). 2006;30(4):618-26.

37. Pahkala K, et al. Ideal cardiovascular health in adolescence: effect of lifestyle intervention and association with vascular intima-media thickness and elasticity (the Special Turku Coronary Risk Factor Intervention Project for Children [STRIP] study). Circulation. 2013;127(21):2088-96.

38. Rolland-Cachera MF, et al. Influence of macronutrients on adiposity development: a follow up study of nutrition and growth from 10 months to 8 years of age. Int J Obes Relat Metab Disord. 1995;19(8):573-8.

39. Gunther AL, et al. Early protein intake and later obesity risk: which protein sources at which time points throughout infancy and childhood are important for body mass index and body fat percentage at $7 \mathrm{y}$ of age? Am J Clin Nutr. 2007;86(6):1765-72.

40. Gunther AL, Buyken AE, Kroke A. Protein intake during the period of complementary feeding and early childhood and the association with body mass index and percentage body fat at $7 \mathrm{y}$ of age. Am J Clin Nutr. 2007;85(6):1626-33.

41. Koletzko B, et al. Lower protein in infant formula is associated with lower weight up to age $2 \mathrm{y}$ : a randomized clinical trial. Am J Clin Nutr. 2009;89(6):1836-45.

42. Escribano J, et al. Effect of protein intake and weight gain velocity on body fat mass at 6 months of age: The EU Childhood Obesity Programme. Int J Obes (Lond). 2012;36:548-53.

43. Koletzko B, et al. Can infant feeding choices modulate later obesity risk? Am J Clin Nutr. 2009;89(5):1502S-8S.

44. Larnkjaer A, et al. The effects of whole milk and infant formula on growth and IGF-I in late infancy. Eur $\mathbf{J}$ Clin Nutr. 2009;63(8):956-63.

45. Dube K, et al. Complementary food with low (8\%) or high (12\%) meat content as source of dietary iron: a double-blinded randomized controlled trial. Eur J Nutr. 2010;49(1):11-8.

46. Krebs NF, et al. Meat as a first complementary food for breastfed infants: feasibility and impact on zinc intake and status. J Pediatr Gastroenterol Nutr. 2006;42(2):207-14.
47. • Krebs NF, et al. Effects of different complementary feeding regimens on iron status and enteric microbiota in breastfed infants. J Pediatr. 2013;163(2):416-23, e4. The results of this study emphasizes the frequency of iron deficiency in healthy breastfed infants fed according to current recommendations. It also indicates an impact of feeding regimen on the infant microbiome.

48. •- Krebs NF, et al. Comparison of complementary feeding strategies to meet zinc requirements of older breastfed infants. Am J Clin Nutr. 2012;96:30-5. This study illustrates the dependence of the older breastfed infant on either fortified foods or naturally rich food sources such as meat to meet zinc requirements.

49. Hoppe C, et al. High intakes of skimmed milk, but not meat, increase serum IGF-I and IGFBP-3 in eight-year-old boys. Eur J Clin Nutr. 2004;58(9):1211-6.

50. Michaelsen KF, Larnkjaer A, Molgaard C. Amount and quality of dietary proteins during the first two years of life in relation to NCD risk in adulthood. Nutr Metab Cardiovasc Dis. 2012;22(10): 781-6.

51. Hornell A, et al. Protein intake from 0 to 18 years of age and its relation to health: a systematic literature review for the 5th Nordic Nutrition Recommendations. Food Nutr Res. 2013;57.

52. Food and Nutrition Board and Institute of Medicine. Dietary reference intakes for vitamin $\mathrm{A}$, vitamin $\mathrm{K}$, boron, chromium, copper, iodine, iron, manganese, molybdenum, nickel, silicon, vanadium and zinc. Standing Committee on the Scientific Evaluation of Dietary Reference Intakes. Washington, DC: National Academy Press; 2001. p. 442-501.

53. Levine A, et al. Screening criteria for diagnosis of infantile feeding disorders as a cause of poor feeding or food refusal. J Pediatr Gastroenterol Nutr. 2011;52(5):563-8.

54. Krebs NF. Update on zinc deficiency and excess in clinical pediatric practice. Ann Nutr Metab. 2013;62(Suppl 1):19-29.

55. Schneider JM, et al. The prevalence of low serum zinc and copper levels and dietary habits associated with serum zinc and copper in 12- to 36-month-old children from low-income families at risk for iron deficiency. J Am Diet Assoc. 2007;107(11):1924-9.

56. Skinner JD, et al. Fruit juice intake is not related to children's growth. Pediatrics. 1999;103(1):58-64.

57. Emmett P, North K, Noble S. Types of drinks consumed by infants at 4 and 8 months of age: a descriptive study. The ALSPAC Study Team. Public Health Nutr. 2000;3(2):211-7.

58. Dennison BA, Rockwell HL, Baker SL. Excess fruit juice consumption by preschool-aged children is associated with short stature and obesity. Pediatrics. 1997;99(1):15-22.

59. Alexy U, et al. Fruit juice consumption and the prevalence of obesity and short stature in german preschool children: results of the DONALD Study. Dortmund Nutritional and Anthropometrical Longitudinally Designed. J Pediatr Gastroenterol Nutr. 1999; 29(3):343-9.

60. Faith MS, et al. Fruit juice intake predicts increased adiposity gain in children from low-income families: weight status-byenvironment interaction. Pediatrics. 2006;118(5):2066-75.

61. American Academy of Pediatrics. The use and misuse of fruit juice in pediatrics. Pediatrics. 2001;107(5):1210-3.

62. Dattilo AM, et al. Need for early interventions in the prevention of pediatric overweight: a review and upcoming directions. J Obes. 2012;2012:123023.

63. Bouhlal S, Issanchou S, Nicklaus S. The impact of salt, fat and sugar levels on toddler food intake. Br J Nutr. 2011;105(4): 645-53.

64. Elliott CD. Sweet and salty: nutritional content and analysis of baby and toddler foods. J Public Health. 2011;33(1):63-70.

65. Anzman SL, Rollins BY, Birch LL. Parental influence on children's early eating environments and obesity risk: implications for prevention. Int J Obes (Lond). 2010;34(7):1116-24. 
66. Forestell CA, Mennella JA. Early determinants of fruit and vegetable acceptance. Pediatrics. 2007;120(6):1247-54.

67. Sullivan SA, Birch LL. Infant dietary experience and acceptance of solid foods. Pediatrics. 1994;93(2):271-7.

68. Mennella JA, Jagnow CP, Beauchamp GK. Prenatal and postnatal flavor learning by human infants. Pediatrics. 2001;107(6):E88.

69. Mennella JA, Trabulsi JC. Complementary foods and flavor experiences: setting the foundation. Ann Nutr Metab. 2012;60(Suppl 2):40-50.

70. Butte N, et al. The start healthy feeding guidelines for infants and toddlers. J Am Diet Assoc. 2004;104(3):442-54.

71. Paul IM, et al. Opportunities for the primary prevention of obesity during infancy. Adv Pediatr. 2009;56:107-33.

72. Adair AL, Thompson LS, Bentley ME. Pressuring and restrictive feeding styles influence infant feeding and size among a lowincome African-American sample. Obesity (Silver, Spring). 2013;21(3):562-71.

73. Brown A, Lee M. Maternal child-feeding style during the weaning period: association with infant weight and maternal eating style. Eat Behav. 2011;12(2):108-11.

74. Rhee KE, et al. Parenting styles and overweight status in first grade. Pediatrics. 2006;117(6):2047-54.

75. Black MM, Aboud FE. Responsive feeding is embedded in a theoretical framework of responsive parenting. J Nutr. 2011;141(3):490-4.

76. Ciampa PJ, et al. Interventions aimed at decreasing obesity in children younger than 2 years: a systematic review. Arch Pediatr Adolesc Med. 2010;164(12):1098-104.
77. French GM, et al. An evaluation of mother-centered anticipatory guidance to reduce obesogenic infant feeding behaviors. Pediatrics. 2012;130(3):e507-17.

78. Fisher JO, et al. Breast-feeding through the first year predicts maternal control in feeding and subsequent toddler energy intakes. J Am Diet Assoc. 2000;100(6):641-6.

79. DiSantis KI, Hodges EA, Fisher JO. The association of breastfeeding duration with later maternal feeding styles in infancy and toddlerhood: a cross-sectional analysis. Int J Behav Nutr Phys Act. 2013;10:53

80. Brown A, Lee M. Breastfeeding during the first year promotes satiety responsiveness in children aged 18-24 months. Pediatr Obes. 2012;7(5):382-90.

81. Daniels LA, et al. Outcomes of an early feeding practices intervention to prevent childhood obesity. Pediatrics. 2013;132(1):e109-18.

82. Daniels LA, et al. Evaluation of an intervention to promote protective infant feeding practices to prevent childhood obesity: outcomes of the NOURISH RCT at 14 months of age and 6 months post the first of two intervention modules. Int J Obes (Lond). 2012;36(10):1292-8.

83. Weng SF, et al. Systematic review and meta-analyses of risk factors for childhood overweight identifiable during infancy. Arch Dis Child. 2012;97(12):1019-26. 